DATE:

SUBJECT:

TO:

FROM:

Purpose:

Sites Visited:

Abstract:
December 21, 1990

Report of Foreign Travel of L. W. Weston, Group Leader, Engineering Physics and Mathematics Division

Alvin W. Trivelpiece

Lawrence $\mathrm{W}$. Weston

Serve as USA representative on two NEACRP/NEANDC Evaluation Cooperation Subgroups and as a CSEWG(USA) observer to the Joint Evaluation File (JEF, European) meeting.

12/3-6/1990 NEA Data Bank, Saclay, France.

The Evaluation Cooperation Subgroup, "Actinide Data in the Thermal Energy Range," met primarily to discuss problems related to the temperature coefficient of U-235 fueli $d$ thermal reactors and nuclear data on eta at thermal neutron energies, the number of neutrons emitted per neutron absorbed. The preliminary results of the eta measurements done by M. Moxon of Harwell at Oak Ridge were presented and preliminary results by $\mathrm{H}$. Weigman of Geel with a new method were presented. All three measurements from Geel show a pronounced down-slope of eta with decreasing neutron energy and both measurements by Moxon show only a very slight down slope. Acceptance of the Geel results would solve about one-third of the problem in the calculated reactor temperature coefficient.

The Evaluation Cooperation Subgroup, "239-Pu Fission C:oss Sections between 1 and $100 \mathrm{keV}$," met to discuss the $4 \%$ lower than the previously evaluated fission cross sections between $20 \mathrm{eV}$ and $100 \mathrm{keV}$ as evaluated from the fission data of the Weston and Todd and transmission data of J. A. Harvey (all of ORNL). These lower fission cross sections are discrepant with integral measurements, however, it is conceivable that there could be compensating effects, perhaps in the U-238 cross sections.

A gencral meeting and a benchmark testing session of the JEF (European Joint Evaluation File) were attended as a representative of CSEWG (USA Cross Section Evaluation Working Group) JEF-2.2 is scheduled for general release after about another year of testing. Cooperation in evaluation of nuclear data between Europe, Japan, and the US has increased dramatically in the last few years because of manpower limitations.

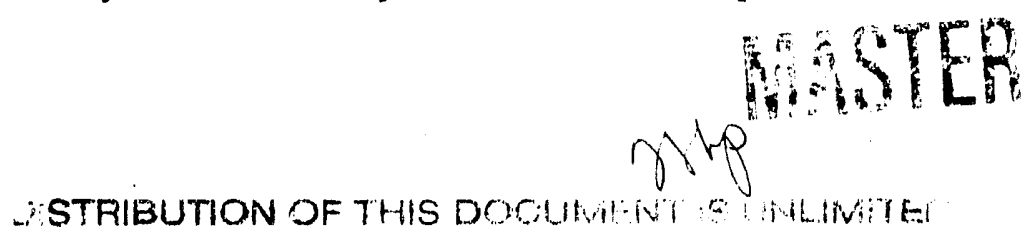




\section{PURPOSE OF TRAVEL}

The second most important aspect of the trip was to attend the Evaluation Cooperation Subgroup Meeting, "Actinide Data in the Thermal Energy Range," held on December 3, 1990. This subgroup is concerned with the discrepancy in calculating the temperature coefficient of thermal reactors and with measurements of eta, the number of neutrons released per neutron absorbed in U-235. It ras been proposed that the problem in calculating the temperature coefficient of thermal reactors is a discrepancy in eta measurements versus

neutron energy at near thermal neutron energies. This is important for ENDF/B supported by DOE as well as the other international nuclear data evaluations. Recent measurements have been carried out at ORNL, Harwell, England, and at Geel, Belgium and representatives of these institutions were present as well as other interested parties. The experimental data continues to be discrepant and the extreme case will account for only one-third of the reactor temperature coefficient problem.

The most important purpose of the trip was to attend the meeting of the Evaluation Cooperation Subgroup, "239-Pu Fission Cross Sections between 1 and $100 \mathrm{keV}$," held on Dec. 4,1990 . This subgroup is concerned with the evaluation problem illuminated by the fission cross section measurements of the traveler and the transmission measurements of $\mathrm{J}$. A. Harvey, both measurements being made at the ORELA. This is a serious nuclear data evaluation problem because if these measurements are correct and the fission and total cross sections for $\mathrm{Pu}-239$ are $4 \%$ lower than the average of previous measurements from $20 \mathrm{eV}$ to $100 \mathrm{keV}$, then there must be compensating discrepancies in other data. Integral measurements would not permit such a change without other compensating effects. This is important for the US Evaluated Nuclear Data File (ENDF/B) supported by DOE, the European Joint Evaluated File (JEF) and the Japanese Evaluated Nuclear Data Library (JENDL).

The other aspect of the trip was to act as a US representative of CSEWG (Cross Section Evaluation Working Group) at the European JEF (Joint Evaluated File) meeting. There has been much cooperation in evaluations for the US ENDF/B-VI released June 1990, the European JEF-2.2 which should be released in about a year and the Japanese JENDL-3 which was released in 1990. Many of the problems are common to all three evaluations and information exchange is very important because of manpower limitations.

\section{SUMMARY OF SUBGROUP MEETING, "ACTINIDE DATA IN THE THERMAL ENERGY RANGE," December 3, 1990}

The basic problems with the cross sections and parameters of the actinides were reviewed by the chairman, H. Tellier. He presented recent results from Geel, Belgium on the U-238 capture cross section in the thermal region to show that the shape is $1 / \mathrm{v}$; no problems or surprises. He reviewed the nu (neutrons per fission) measurements primarily of $\mathrm{Gwin}$ at ORNL to show there were no apparent problems for U-235 or Pu-239. He discussed how

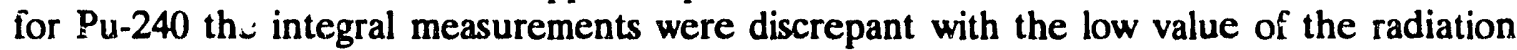
width of the $1 \mathrm{eV}$ resonance as measured by $\mathrm{R}$. Spencer at ORELA. This has been a very long standing problem. The primary discrepancy of interest was the problem with calculating the temperature coefficient of thermal reactors fueled by U-235 and the discrepancy in recent measurements of eta (number of neutrons per absorption). 
M. Sowerby of Harwell, England presented the preliminary measurements done in early 1990 at ORELA by M. Moxon. These measurements were in complete agreement with earlier measurements by M. Moxon at the Harwell Linac. The Moxon measurements indicate only a very slight down-slope of eta with decreasing neutron energy below the $0.3 \mathrm{eV}$ resonance. This is in disagreement with measurements by $\mathrm{H}$. Weigman and others of Geel who did measurements at Geel and Grenoble which indicated a marked down-slope with decreasing neutron energy. The Moxon measurements at ORNL used different samples and equipment than the measurements at Harwell. The Weigman measurements at Geel and Grenoble used essentially the same equipment except for the Geel Linac and the Grenoble reactor.

H. Weigman presented very new preliminary measurements of eta for U-235 done with a different method. This was basically a measurement of alpha, the ratio of capture to fission cross sections, but values of eta can be inferred since nu is flat in this neutron energy region. Gamma rays from a very thin U-235 sample were observed with a Ge-Li detector and particular gamma-rays from capture and fission events were observed. There were backgrounds from other unresolved gamma-rays but this problem was not too severe. This measurement makes the assumption that the gamma-ray cascades from capture and from fission events do not change with neutron energy in the energy range of concern. These new measurements were in excellent agreement with earlier Geel measurements.

There was discussion whether the measured shapes of eta versus neutron energy could be fit by Reich-Moore resonance theory. The author showed the results of deSaussure, Leal and Perez of ORNL which indicated that the downslope could be fitted assuming a small resonance with almost zero fission width near zero neutron energy. This was argued to have a very small probability, which is true but there is just such a resonance in U-233 at $0.15 \mathrm{eV}$. Thus, theory is of little help.

The score is now 3 to 2 in favor of Geel! Geel has three measurements which agree and Harwell has 2 measurements which agree. Measurements are planned at ORELA with the new multi-crystal spectrometer, however, results will probably not be achieved for about 2 years.

\section{SUMMARY OF THE SUBGROUP MEETING, 239-PU FISSION CROSS SECTIONS BETWEEN 1 and 100 keV," December 4, 1990}

The purpose of this subgroup is to try to understand the evaluation problem presented by the fission cross section measurements of Weston and Todd and the transmission measurements of J. A. Harvey. These measurements indicate a fission cross section for Pu-239 about $4 \%$ lower than the average of the previously reported data in the neutron energy range from 20 $\mathrm{eV}$ to $100 \mathrm{keV}$. This creates a serious discrepancy for integral measurements and previous evaluations of nuclear data for both thermal and fast reactors. It had been previously agreed that the subgroup would attack this problem according to three aspects: experimental, theoretical and integral aspects.

\section{Experimental Aspects}

The discussion of the experimental aspects was led by the two experimentalists at the meeting; C. Wagemans from Geel and the author. Because of documentation previously circulated to the subgroup by the author, it was quickly agreed that the problem was one of normalization 
and not involved with the shape versus neutron energy of the average fission cross section. Thus, the problem is not in the $\mathrm{keV}$ range of neutron energies but below $20 \mathrm{eV}$ since the data was normalized at thermal neutron energy. Wagemans provided integrated data to show that there could very well be an uncertainty of $4 \%$ in the normalization of previous data. Only the data of Gwin of ORNL had measured the fission cross section in one experimental measurement simultaneously from thermal to at least $100 \mathrm{keV}$. Other experiments contained various internormalizations.

H. Derrien (CEA, retired) discussed his Reich-Moore resonance parameter fit to the resonance region of $\mathrm{Pu}-239$ and how this fit was consistent with the fission data of Weston and the transmission data of 'Harvey and not other previous data. Through this resonance parameter fit, the transmission data confirms the normalization of the fission data. A reriormalization of the Weston fission data would have caused inconsistencies with the shape of the transmission data. He also pointed out the only other set of very high resolution fission cross section data by Blons appeared to have a somewhat flat background cross section between resonance which forced a normalization about $4 \%$ too high.

The conclusion from the experimental aspects was that the basic discrepancy is one of normalization and background cross section. Both ORNL and Geel will carry out experiments to obtain data with which to better normalize previous measurements. Efforts will be made to complete the measurements by the end of 1991 .

\section{Theoretical Aspects}

H. Derrien discussed the Pu-239 cross sections in the energy range from 1 to $500 \mathrm{keV}$. The Harvey (ORNL) transmission measurements were analyzed and corrected for self-shielding such that a total cross section was obtained with an accuracy of about $2 \%$. A report covering this work is available and provides a significant improvement to the data base. These average total cross section measurements tend to confirm the Weston fission data and conflict with previous evaluations.

C. Lagrange (Bruyeres-le-Chatel) had done calculations of optical model parameters and determined that the new as well $a^{-}$the older data could be fit with reasonable optical model parameters. These optical model parameters can be used for further calculation of integral parameters.

M. Kawai (Toshiba Corp.) reported on the work of himself and T. Nakagawa to survey the cross sections for Pu-239 in the energy region 1-100 keV. It was noted that the uncertainty in the competitive cross sections, particularly the capture cross sections or alpha, were large compared to those in the fission cross sections so that little constraint would be placed on the fission cross sections.

\section{Integrai Aspects}

E. Fort (Cadarache) discussed the integral aspects of the Pu-239 fission data. Of course, a simple lowering of the fission and total cross sections in evaluations over a broad neutron energy range will cause discrepancies with integral experiments. Since the new optical model calculations of Lagrange indicate that inelastic and capture cross sections may also need to be lowered, perhaps effects will compensate. E. Fort will perform statistical calculations with the parameters of Lagrange and P. Young of LANL has been asked to do the same for the 
ENDF/B-VI data base. Benchmark calculations will be performed by E. Fort at Cadarache on the two sets of model calculations. Expected completion of this work is July 1991.

\section{$\underline{\text { Summary of Conclusions }}$}

It was concluded that the major discrepancy between the Weston and previous data is one of normalization. Both Geel and ORNL will carry out new measurements with careful background determinations to derive accurate normalization integrals for the Pu-239 fission cross sections. The average cross section measurements should extend to at least $200 \mathrm{keV}$. Results should be available by the end of 1991 .

C. Lagrange will complete the calculation of new optical model parameters. E. Fort and P. Young will perform statistical calculations considering respectively the Weston data and ENDF/B-VI as reference fission cross sections. Completion should be by March 1991.

Benchmark calculations will be performed at Cadarache by. E. Fort to test the above two evaluations. Expected completion data is July 1991.

\section{JEF Working Group Meeting}

The JEF Working Group on Benchmark Testing on Dec. 5, 1990 and the JEF Working Group on Evaluation on Dec. 6, 1990 were attended by the author as a CSEWG observer. There were about 25 people at the meetings with people coming and going according to their individual interests. JEF-2.1 was released in July 1990 and about a year of data testing is to transpire before the release of the more final JEF-2.2. The working group is adapting NJOY by $\mathrm{R}$. MacFarlane of LASL for processing and members have found a number of corrections necessary.

Most of the benchmark testing which was discussed was for the simple fast systems such as Godiva, Jezebel and Big Ten. JEF-2.1 tends to calculate criticality for all fast systems too low by about $2 \%$, however, this is being remedied for JEF-2.2. With the modifications for JEF-2.2, Big Ten continues to calculate at about $1 \%$ low. There was continued concern over the temperature coefficient problem in thermal reactors. JEF includes thermal solid-state effects in evaluations whereas ENDF does not.

There are problems with JEF in shielding calculations which are probably involved with Fe-56 and Fe-57; part of which may be processing problems. This working group has not accepted the need for Reich-Moore resonance parameters to the extent of the US CSEWG. The author was surprised that JEF is not adopting the ORNL cvaluations for $\mathrm{Fe}, \mathrm{Ni}$ and $\mathrm{Cr}$ since they are clearly superior to previous evaluations in terms of methods and new measurements. The US CSEWG appears more willing to accept foreign evaluations than does JEF of Europe. This is probably influenced by more severe manpower limitations for CSEWG. This attitude should mellow with time and international cooperation.

The problem with capture measurements for $\mathrm{U}-238$ in the lower $\mathrm{keV}$ region of neutron energy being too high as compared to integral experiments continues to exist. The new projected completion date for the resonance region evaluation of U-238 by M. Moxon and M. Sowerby is Sept. 1991. F. Froehner continued to defend his unresolved resonance region evaluation being lower than most of the measured data on the basis of improper resonance 
self-protection corrections for the data. ENDF/B-V accepted Froehner's U-238 evaluation in the unresolved resonance region. There were recent, Russian, highly self-shielded transmission measurements for U-238 which he calculates quite well. Agreement with the RPI capture self-shielding measurements is poor; he thinks the measurements are wrong. Such measurements have been tried at ORELA by Yang, deSaussure and Perez and it was found that accurate measuurements were quite difficult because of background and neutron scaltering corrections.

The JEF working group is very similar to the US counterpart, CSEWG, in most ways. The most noticeable difference is that CSEWG is more compartmentalized into committees. This is a carry over from when CSEWG had a much larger attendance so that the differences between the JEF working group and CSEWG will probably diminish in the future.

\section{SUMMARY EVALUATION OF TRIP}

The Evaluation Cooperation Subgroup meetings were quite productive. There continue to exist severe nuclear data evaluation problems and since no one country is supporting a level of effort to effectively solve these problems, international cooperation is essential. Since the US is no longer dominant in such matters, it has much to gain from international cooperation.

As a CSEWG representative to the JEF working group, much was learned of the European operation of producing evaluated nuclear data files. International cooperation in evaluations is rapidly growing; especially along informal lines. Evaluations and parts of evaluations are usually readily accepted by CSEWG, JEF and JENDL when they are obviously of high quality. Contact amoung the international group of evaluators is essential for this valuable exchange of information. Eventually there will probably be an international evaluated nuclear data file, however, it is the opinion of the author that the more informal international cooperation is the more valuable at the present time. 


\section{APPENDIX}

ITINERARY

December 1-2, 1990 Travel to Paris, France.

December 3-6,1990 Attend Evaluation Cooperation Subgroup meetings and JEF Warking Group meetings at the NEA Data Bank, Saclay, France.

December 7, $1990 \quad$ Vacation

December 8, $1990 \quad$ Weekend

December 9, 1990 Travel from Paris, France to Oak Ridge, Tennessee.

\section{DISCLAIMER}

This report was prepared as an account of work sponsored by an agency of the United States Government. Neither the United States Government nor any agency thereof, nor any of their employees, makes any warranty, express or implied, or assumes any legal liability or responsibility for the accuracy, completeness, or usefulness of any information, apparatus, product, o: process disclosed, or represents that its use would not infringe privately owned rights. Reference herein to any specific commercial product, process, or service by trade name, tradernark, manufacturer, or otherwise does not necessarily constitute or imply its endorsement, recommendation, or favoring by the United States Government or any agency thereof. The views and opinions of authors expressed herein do not necessarily state or reflect those of the United States Government or any agency thereof. 


\section{CONTACTS}

Evaluation Subgroup Meetings:

$\begin{array}{lll}\text { M. Caro } & \text { PSI Wurenlingen } & \text { Switzerland } \\ \text { H. Derrien } & \text { CEA (Retired) } & \text { France } \\ \text { E. Fort } & \text { Cadarache } & \text { France } \\ \text { M. Kawai } & \text { Toshiba Corp. } & \text { Japan } \\ \text { Y. Kikuchi } & \text { JAERI } & \text { Japan } \\ \text { C. Lagrange } & \text { Bruyeres-le-Chatel } & \text { France } \\ \text { M. Sowerby } & \text { Harwell } & \text { UK } \\ \text { H. Tellier } & \text { CEN Saclay } & \text { France } \\ \text { A. Tobias } & \text { Nuclear Electic } & \text { UK } \\ \text { C. Wagemans } & \text { CBNM Geel } & \text { Belgium } \\ \text { H. Weigman } & \text { CBNM Geel } & \text { Belgium } \\ \text { L. Weston } & \text { ORiJL } & \text { USA }\end{array}$




\section{LTERATURE ACQUIRED}

H. Derrien, "Pu-239 Total Cross Sections in the Energy Range $1 \mathrm{keV}$ to $500 \mathrm{keV}$," JEF/DOC291.

E. Fort, "Proposals for JEF2 Validation, Cadarache," Sept. 1990.

"GRAPHICAL COMPARISON OF SOME DOSIMETRY CROSS SECTIONS, NEA Data Bank," JEF/DOC-323, Dec. 1990.

JEF WORKING GROUP ON BENCHMARK TESTING, ADK/90/M53, December 5,1990.

Minutes (and handouts) of Meeting of sub-group 5: "239-Pu Fission Cross Sections between $1 \mathrm{keV}$ and $100 \mathrm{keV}$," December 4, 1990.

Progress report on sub-group 4, "U-238 Capture and Inelastic Scattering Cross Sections."

E. Sartori, "VITAMIN-J, ECCO-33, ECCO-2-- and XMAS, STANDARD GROUP CROSS SECTION LIBRARY STRUCTURES FOR REACTOR SHIELDING, REACTOR CELL' AND FUSION NEUTRONICS APPLICATIONS," JEF/DOC-315, Revision 2-DRAFT, Dec. 3, 1990.

"Status of the JEF-2 Library," JEF/DOC-322, December 1990.

"Summary Record of the JEF Working Groups on Evaluation and Benchmark testing," JEF/DOC-319, NEA Data Bank, 30th and 31 st, May 1990.

"VITAMIN-J from JEF-2 rev.1 processed with NJOY-89.up62mm, Preliminary Results," IKE, Sept. 1990.

C. Wagemans, "Low Energy Cross-Sections of the Major U and Pu Isotopes," Draft, IAEA Technical Report Series, 1988. 

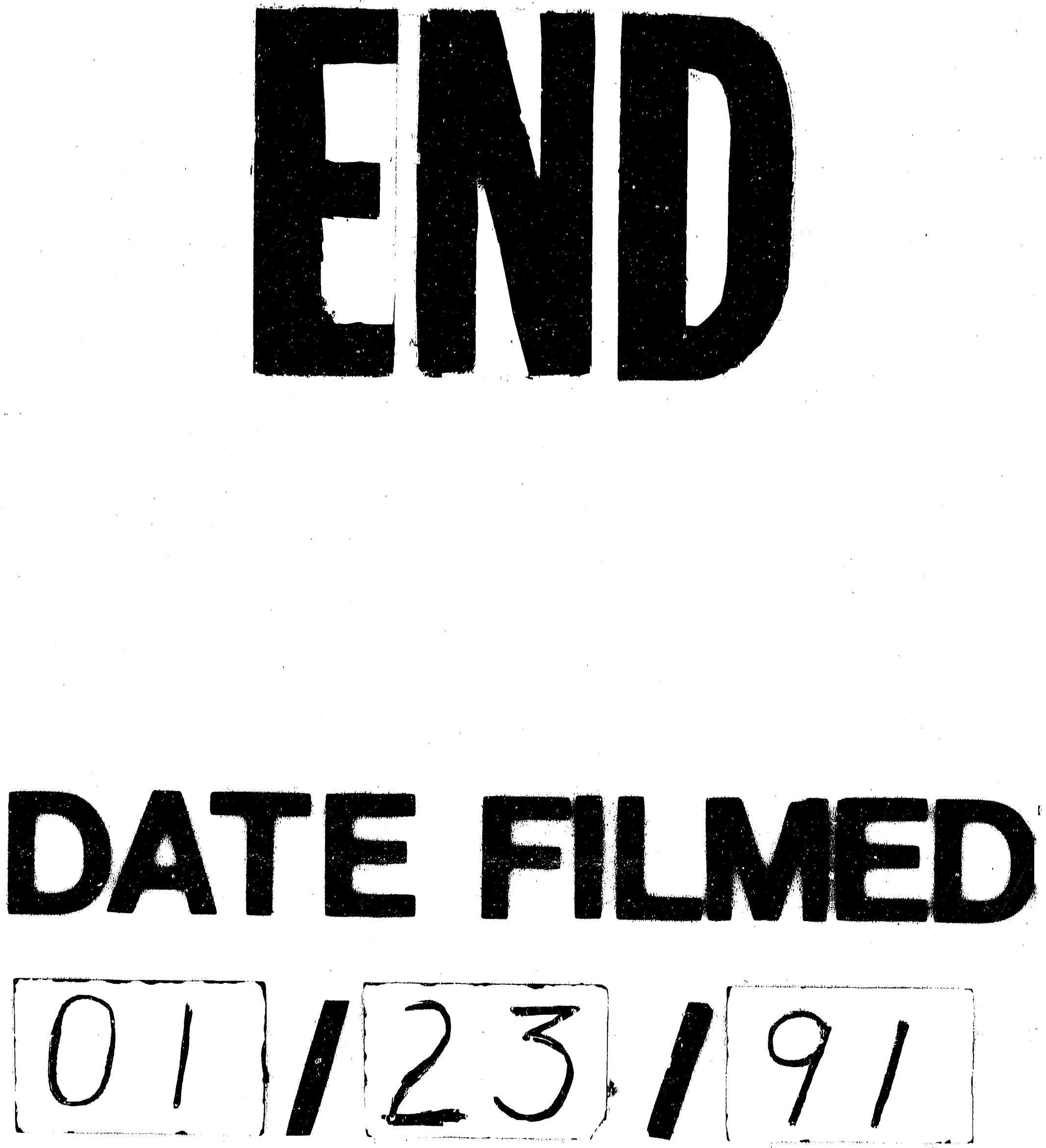


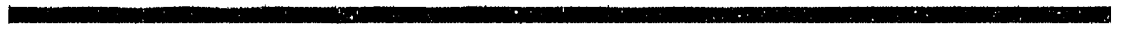

